Ecological Applications, 1996, v.6, n.1, pp.152-167.

ISSN: 1051-0761

DOI: $10.2307 / 2269561$

http://www.esajournals.org/loi/ecap

http://www.esajournals.org/doi/abs/10.2307/2269561

(c) 1996. All rights reserved. Ecological Society of America. 


\title{
ASSESSING POPULATION RESPONSES TO MULTIPLE ANTHROPOGENIC EFFECTS: A CASE STUDY WITH BROOK TROUT ${ }^{1}$
}

\author{
Elizabeth A. Marschall \\ Department of Zoology, The Ohio State University, Columbus, Ohio 43210 USA \\ LARRY B. CROWDER ${ }^{2}$ \\ Department of Zoology, North Carolina State University, Raleigh, North Carolina 27695-7617 USA
}

\begin{abstract}
Population declines are often caused by multiple factors, including anthropogenic ones that can be mitigated or reversed to enhance population recovery. We used a size-classified matrix population model to examine multiple anthropogenic effects on a population and determine which factors are most (or least) important to population dynamics. We modeled brook trout (Salvelinus fontinalis) in southern Appalachian mountain streams responding to multiple anthropogenic effects including the introduction of an exotic salmonid species (rainbow trout, Oncorhynchus mykiss), a decrease in $\mathrm{pH}$ (through acidic deposition), an increase in siltation (from roadbuilding and logging), and an increase in fishing pressure.
\end{abstract}

Potential brook trout responses to rainbow trout include a decrease in survival rate of small fish, a change in density dependence in survival of small fish, and a decrease in growth rates of all sizes. When we included these responses in the population model, we found that population size tended to decrease with an increase in small-fish growth rate (producing a population with fewer, but larger, fish). In addition, changes in patterns of density-dependent survival also had a strong impact on both population size and size structure. Brook trout respond to decreases in $\mathrm{pH}$ with decreased growth rate in all size classes, decreased survival rates of small fish, and decreased egg-to-larva survival rates. This combination of effects, at magnitudes documented in laboratory experiments, had severe negative impacts on the modeled population. If siltation effects were severe, the extreme increase in egg-to-larva mortality could have strong negative effects on the population. However, even very strong increases in large fish mortality associated with sport harvesting were not likely to cause a local extinction. In all of these cases, the interaction of drastic changes in population size structure with randomly occurring floods or droughts may lead to even stronger negative impacts than those predicted from the deterministic model.

Because these fish can reproduce at a small size, negative impacts on survival of the largest fish were not detrimental to the persistence of the population. Because survival of small juveniles is density dependent, even moderate decreases in survival in this stage had little effect on the ultimate population size. In general, a brook trout population will respond most negatively to factors that decrease survival of large juveniles and small adults, and growth rates of small juveniles.

Key words: angler effect; anthropogenic effects; Appalachian mountain streams; brook trout; exotic species; local extinction; matrix population modeling; rainbow trout; size structure; stream acidification; stream salmonids.

\section{INTRODUCTION}

For many endangered and threatened species as well as for species harvested recreationally or commercially, population declines are caused by multiple factors. Many of these effects are anthropogenic and often can be mitigated or reversed (at some cost) to enhance population recovery. But often researchers and managers address only one or a few particular factors deemed important (on political, economic, or biological grounds) to the population in question. Here we con-

\footnotetext{
${ }^{1}$ Manuscript received 9 August 1993; revised 20 January 1995; accepted 20 January 1995; final version received 6 March 1995.

2 Present address: Duke University Marine Laboratory, Beaufort, North Carolina 28516-9721 USA.
}

sider multiple anthropogenic effects on a population and determine which factors (and factor interactions) are most important to population size and size structure. We provide an approach that allows us to eliminate some factors as relatively unimportant.

We used a size-classified population model to translate the growth and survival responses of individuals to environmental perturbations into population level responses (Caswell and John 1992, Murdoch 1993). Models of populations structured by space, size, age, or sex have been developed to translate changes in life history parameters into population and community responses in a variety of ecological systems (see, e.g., Metz and Diekmann 1986, Ebenman and Persson 1988, Caswell and John 1992). Matrix population models have been particularly useful in projecting population 
TABLE 1. Summary of potential growth and survival responses of individual brook trout to species introduction, habitat alteration, and harvesting.

\begin{tabular}{|c|c|c|c|}
\hline $\begin{array}{c}\text { Anthropogenic } \\
\text { effect }\end{array}$ & Stage & Individual responses & $\begin{array}{l}\text { Model } \\
\text { parameters } \\
\text { affected }\end{array}$ \\
\hline Species introduction & $\begin{array}{l}\text { Juvenile: } \\
\text { Adult: }\end{array}$ & $\begin{array}{l}\text { decrease survival probability } \\
\text { decrease growth rate } \\
\text { change slope of density-dependent survival } \\
\text { decrease growth rate }\end{array}$ & $\begin{array}{l}\boldsymbol{R} \\
\boldsymbol{P} \\
C_{1} \\
\boldsymbol{P}\end{array}$ \\
\hline Harvesting increase & Adult: & decrease survival probability & $\boldsymbol{R}$ \\
\hline Siltation increase & Egg: & decrease egg to larva survival & $w_{0}$ \\
\hline Acidic deposition & $\begin{array}{l}\text { Egg: } \\
\text { Juvenile: }\end{array}$ & $\begin{array}{l}\text { decrease egg to larva survival } \\
\text { decrease survival probability } \\
\text { decrease growth rate }\end{array}$ & $\begin{array}{l}w_{0} \\
\boldsymbol{R} \\
\boldsymbol{P}\end{array}$ \\
\hline & Adult: & decrease growth rate & $\boldsymbol{P}$ \\
\hline
\end{tabular}

responses to changes observed in life history parameters (Bierzychudek 1982, Burns and Ogden 1985, Caswell 1989, Caswell and John 1992). These models have been used in a variety of ways, but they are particularly valuable in identifying potential responses of populations to predicted changes in their environments or to planned mitigation by managers (Horst 1977, Evans and Dempson 1986, Crouse et al. 1987). In this study, we have developed a matrix population model to project population consequences of changes in life history parameters brought on by changes in the environment, specifically for headwater stream fish populations.

Throughout the past century, southern Appalachian headwater streams inhabited by native populations of brook trout (Salvelinus fontinalis) have experienced a number of changes, most of them anthropogenic. The most important of these include the introduction of exotic salmonid species, a decrease in $\mathrm{pH}$ (through acidic deposition), an increase in siltation and a decrease in shade (from timber harvesting), and an increase in fishing pressure. Brook trout have declined in abundance; their distribution within these streams has become limited to the uppermost headwaters (Kelly et al. 1980, Larson and Moore 1985).

To understand either the decline of brook trout or the maintenance of their reduced distribution in the southern Appalachians, we must understand the population consequences of each type of potential ecological pressure. We can group specific ecological pressures based on how they affect individual brook trout, and then characterize each group of like pressures as to the type and severity of its consequences to the population as a whole.

We begin by characterizing the potential growth and survival responses of individual brook trout to species introduction, habitat alteration, and harvesting. We then describe a general model of a southern Appalachian brook trout population and assess the sensitivity of the modeled population to changes in growth and survival at different life stages. In this way, we can simulate the ecological effects of competition, predation, habitat degradation, and harvesting. And finally, we compare the potential population consequences of each of these phenomena.

\section{ANTHROPOGENIC EFFECTS}

\section{Species introduction}

During the early part of this century, rainbow trout (Oncorhynchus mykiss) were introduced into. southern Appalachian mountain streams (King 1937, Kelly et al. 1980). They have expanded their distribution within these streams and currently overlap brook trout distributions extensively (Larson and Moore 1985). Allopatric populations of book trout occur in the headwaters of these mountain streams, allopatic populations of rainbow trout occur farther downstream, and a zone of sympatry occurs between (Larson and Moore 1985).

Rainbow trout have potential for a variety of effects on brook trout. Although there are tendencies for some differences in habitat use by adults of the two species (Larson and Moore 1985), adult habitat use still overlaps greatly between the species (Cunjak and Green 1983, Lohr and West 1992), and intraspecific differences in habitat use between allopatric and sympatric populations indicate that these two species are interacting when together (Cunjak and Green 1983, Lohr and West 1992). Adults of these two species compete for feeding territories, and ability to hold a feeding territory is most strongly a function of body size (Newman 1956, Cunjak and Green 1984). We do not expect a direct mortality response of adult brook trout to competition with adult rainbow trout. Rather, we expect a more subtle response: a reduction in adult brook trout growth rate (Table 1). Because age-0 fish (i.e., fish in their first summer of growth) of the two species also overlap greatly in habitat use and diet (Larson and Moore 1985, Lohr and West 1992), we should see competitive effects similar to those proposed for adults. If age- 0 brook trout and age- 0 rainbow trout are competing, then we expect age- 0 brook trout to respond with a reduction in growth rate (Table 1).

The potential effects of large rainbow trout on small, age- 0 brook trout are more complex than the effects of similar-sized fish. There are three important ways in 
which large rainbow trout may affect these small brook trout. They may have a lethal predatory effect, resulting in a decrease in instantaneous survival rate while brook trout are small enough to be prey. They may have a nonlethal predatory effect that results in small brook trout changing habitat to avoid predation, but suffering a decrease in growth rate as a result. They may also have an indirect lethal effect by causing small brook trout to change habitats. Because survival in young stream salmonids is generally density-dependent (Hunt 1965, LeCren 1972) and the actual density that can survive in a particular place is related to habitat characteristics (Kalleberg 1958, Mason and Chapman 1965, Slaney and Northcote 1974, Mortensen 1977, Dill et al. 1981), a change in habitat use may result in a reduction in the number of small brook trout that can survive. These last two potential effects of large rainbow trout on small brook trout may be the result of small brook trout perceiving large rainbow trout either as predators or as superior competitors. Evidence for an effect of large rainbow trout on macrohabitat (Larson and Moore 1985) and microhabitat (Lohr and West 1992) use by age-0 brook trout and growth rate response by age- 0 brook trout to the presence of large rainbow trout (Marschall 1991) indicate the potential importance of these last two responses.

We do not expect strong effects of rainbow trout on reproductive success of brook trout. Because brook trout spawning occurs in the fall and rainbow trout spawn in the spring, interspecific spawning interactions or competition for redd (nest) sites should not occur. There is also no evidence of rainbow trout preying on brook trout eggs (Needham 1961).

\section{Habitat alteration}

We consider alteration of two important habitat variables: siltation and acidity. Following the heavy logging in the early part of this century, Powers (1929) found that distribution of brook trout in Great Smoky Mountains National Park corresponded to uncut areas of the forests. The fires that accompanied logging affected stream habitats even more severely than logging, causing extensive siltation and loss of shade (King 1937). Both road building and logging continue to be important causes of siltation. In addition, increased acid deposition has caused changes in the chemistry of these streams (Cosby et al. 1991), including decreases in $\mathrm{pH}$ and increases in aluminum in the water.

The most prominent effects of siltation are on quality of redd sites. Because egg survival in salmonids is dependent on substrate size (Witzel and MacCrimmon 1983a) and water flow around the interstitial spaces housing the eggs, the effect of siltation should be expressed as a decrease in egg-to-larva survival (Table 1).

There have been extensive studies of brook trout physiological responses to $\mathrm{pH}$ (and the associated changes in aluminum and calcium; see Bergman et al. 1988, Bergman and Mattice 1990). In these softwater mountain streams, a decrease in $\mathrm{pH}$ results in an increase in osmotic imbalance and ionoregulatory failure (Leivestad 1982, Wood and McDonald 1982). In general, survival of eggs, fry, juvenile, and adult brook trout is decreased by a decrease in $\mathrm{pH}$ and calcium (Jordahl and Benson 1987, Ingersoll et al. 1990), though severity of this effect is greatest on youngest age classes. In systems stressed by acidic deposition, growth rates of juveniles and adults are positively correlated with $\mathrm{pH}$ and calcium concentration. Again, the effect is strongest on juveniles (Mount et al. 1988, Ingersoll et al. 1990, Marschall 1991). Neither fecundity (per body mass) nor egg size is affected by $\mathrm{pH}$ and calcium concentration (Mount et al. 1988).

\section{Harvesting}

Although detailed records of sport harvest of brook trout on specific Appalachian mountain streams are rare, we do know that fishing in general has increased in popularity during recent decades. For example, the number of people $\geq 12 \mathrm{yr}$ old who participated in freshwater fishing doubled between 1955 and 1980 (Anonymous 1982), and in $1985, \approx 25 \%$ of the freshwater anglers in the southern Appalachian mountain states consisted of trout anglers (Anonymous 1985). Because most brook trout fishing regulations involve a minimum legal size, sport harvests will have the greatest direct impact on survival rate of large brook trout (Table 1).

\section{Population Model}

The population model is based on a simple sizeclassified projection matrix. We have partitioned the brook trout population into 15 size classes based on total length. Fish between 20 and $100 \mathrm{~mm}$ were classified into $10-\mathrm{mm}$ size classes; remaining fish were classified into $20-\mathrm{mm}$ classes. We chose $10-\mathrm{mm}$ intervals because data are most frequently reported in this form. Using 10-mm classes (or multiples of $10 \mathrm{~mm}$ ) allows comparison of model results to published length-frequency distributions. Finer divisions were used in the small sizes because changes in size here affect survival through the relation between size, number, and density-dependence. At larger sizes, coarser divisions are sufficient to differentiate among size-dependent rates. The resulting size classes are characterized by their midpoints: $25,35,45,55,65,75,85,95$, $110,130,150,170,190,210$, and $230 \mathrm{~mm}$. Although we have not modeled fish $>240 \mathrm{~mm}$, fish in the final size class may remain in that class for several years (depending on the value of the survival rate parameter). We have grouped eggs, larvae, and fish $<20 \mathrm{~mm}$ into one class that represents the portion of the life history spent in and around the nest through the winter. Fish in this class either die over the winter or survive and become part of the first size class at the beginning of the growing season. In addition, although the modeled population is classified by size rather than age, we also kept account of the age- 0 cohort through the growing 
season because we were modeling their survival probabilities as being dependent on the total number and sizes of fish in that cohort.

We have modeled the annual cycle of a brook trout population as consisting of a 6-mo growth period (from spring to fall), fall spawning, overwintering without growth (from spawn until spring), and finally, emergence of larvae and beginning of growth again in the spring. We used monthly time intervals to model the population during the growing season. We chose monthly time intervals because (1) published growth and survival data were frequently measured on this scale and (2) we want to follow changes in size distribution through the growing season. An annual time interval would be too coarse to model density- and sizedependent processes affecting age- 0 fish. Weekly time intervals would require too much interpolation of published monthly and quarterly growth and survival rate estimates.

During growing season $y, N(t+1, y)$, the size distribution at sample time (month) $t+1$, is

$$
N(t+1, y)=Q(t, y) N(t, y) \quad t=0, \ldots, 5,
$$

where $N(t+1, y)$ is a vector with elements $n_{t}(t+1$, $y$ ) representing the number of fish in size class $i$ ( $i=$ $1, \ldots, 15)$ and $\boldsymbol{Q}(t, y)$ is a matrix of transition probabilities calculated from survival and growth rates. $Q(t$, $y)$ can be separated into two parts: (1) a diagonal matrix

- $\boldsymbol{R}(t, y)$ whose diagonal elements are per capita rates of survival, a function of density in age- 0 fish, but densityindependent in older fish, and (2) a constant matrix $\boldsymbol{P}$ containing transition probabilities (given survival) calculated from growth rates. Size distribution dynamics during growing season $y$ are described by

$$
\boldsymbol{N}(t+1, y)=\boldsymbol{P R}(t, y) \boldsymbol{N}(t, y) .
$$

To more clearly illustrate this, we include some sample lines from this product of matrices.

$$
\begin{aligned}
\left(\begin{array}{c}
n_{1}(t+1, y) \\
n_{2}(t+1, y) \\
n_{3}(t+1, y) \\
\vdots \\
n_{14}(t+1, y) \\
n_{15}(t+1, y)
\end{array}\right)= & \left(\begin{array}{ccccccc}
p_{1,1} & 0 & 0 & \cdots & 0 & & 0 \\
p_{2,1} & p_{2,2} & 0 & \cdots & 0 & & 0 \\
p_{3,1} & p_{3,2} & p_{3,3} & \cdots & 0 & & 0 \\
\vdots & \vdots & \vdots & \cdots & \vdots & & \vdots \\
0 & 0 & 0 & \cdots & p_{14,14} & 0 \\
0 & 0 & 0 & \cdots & p_{15,14} & p_{15,15}
\end{array}\right) \\
& \cdot\left(\begin{array}{cccccc}
r(t, y) & 0 & 0 & \cdots & 0 & 0 \\
0 & r(t, y) & 0 & \cdots & 0 & 0 \\
0 & 0 & r(t, y) & \cdots & 0 & 0 \\
\vdots & \vdots & \vdots & \cdots & \vdots & \vdots \\
0 & 0 & 0 & \cdots & R & 0 \\
0 & 0 & 0 & \cdots & 0 & R
\end{array}\right) \\
& \cdot\left(\begin{array}{c}
n_{1}(t, y) \\
n_{2}(t, y) \\
n_{3}(t, y) \\
\vdots \\
n_{14}(t, y) \\
n_{15}(t, y)
\end{array}\right)
\end{aligned}
$$

where $n_{t}(t, y)=$ the number of individuals in size class $i$ at the beginning of month $t, p_{i, j}=$ probability that an individual will be in size class $i$ at the beginning of month $t+1$ given that it was in size class $j$ at the beginning of month $t$ and that it survives over that month, $r(t, y)=$ density-dependent per capita survival probability for age-0 fish (a function of size and number of age-0 fish), and $R=$ density-independent per capita survival probability for all other fish. In the overwinter transition from the end of one growing season $N(6, y)$ to the beginning of the next $N(0, y+1)$, the population adds a new cohort of larvae, suffers some overwinter mortality, but otherwise does not change:

$$
\boldsymbol{N}(0, y+1)=w \boldsymbol{N}(6, y)+\left[\begin{array}{c}
w_{0} \boldsymbol{b}^{\prime} \boldsymbol{N}(6, y) \\
0 \\
\vdots \\
0
\end{array}\right]
$$

where $\boldsymbol{b}^{\prime}$ is a vector of size-dependent fecundities, $w_{0}$ is overwinter survival probability of eggs and larvae, and $w$ is overwinter survival probability of all other individuals. Below, we detail the methods and justification for estimating $\boldsymbol{P}, w, w_{0}, \boldsymbol{R}$, and $\boldsymbol{b}$. Data used in estimating survival parameters were taken from studies of stream resident brook trout whenever they were available. Because of the similarity of processes that control mortality across species within stream salmonids, we also used data from stream populations of brown trout when data on stream populations of brook trout were limited.

\section{Estimating growth rates (matrix $\mathbf{P}$ )}

Each element of $\boldsymbol{P}, p_{t, j}$, gives the probability of an individual being in size class $i$ at the beginning of a sample period (during the growing season) given that it was in class $j$ at the beginning of the previous period and that it survives over that period. Ideally, these transition rates would be calculated from growth data on individually marked fish. In this way, growth rates could be completely separated from size-dependent survival rates. These data, however, are not available. Instead, we used changes in mean length of cohorts of fish measured throughout the year. Data were restricted to those for stream populations of native brook trout. Growth measurements required individual length measurements on a single cohort of trout, repeated over time. We found five such data sets: three from Wisconsin and Michigan populations (Cooper 1953, McFadden 1961, Miller 1970) and two from North Carolina and Tennessee populations (Whitworth and Strange 1983, Urwick 1986). From each of these studies, a monthly growth rate for each sample date for each cohort sampled was calculated, providing a total of 96 estimates of average growth rates. Fish sizes were represented by mean size of individuals within the cohort on each date, so growth rates were estimated as the change in mean length (in millimetres) of the cohort 


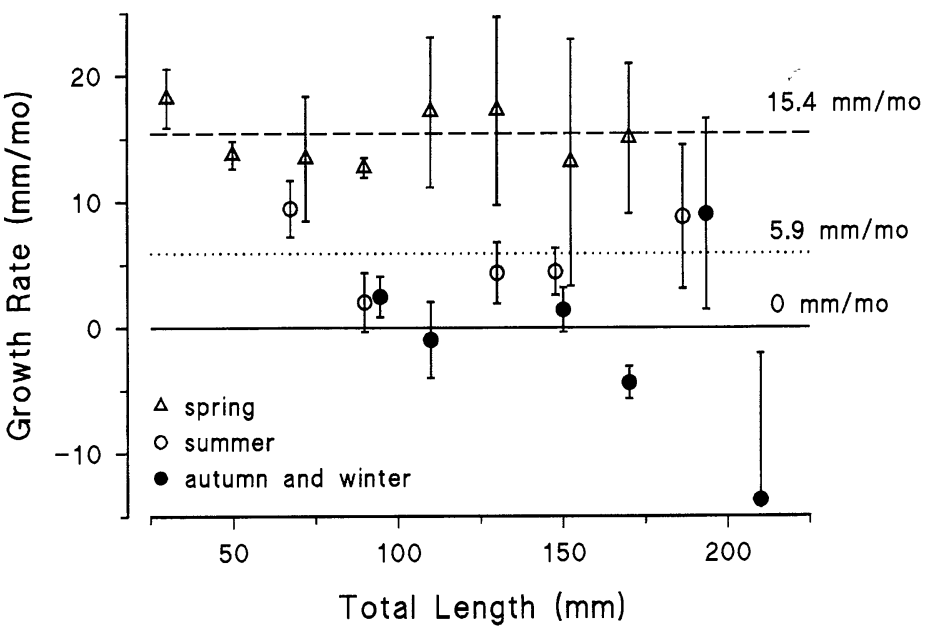

FIG. 1. Monthly growth rate (data represent mean $\pm 1 \mathrm{SE}$ ) in stream populations of native brook trout as a function of body size during spring (April through June, $\Delta---$ ), summer (July through September, $\bigcirc \cdots \cdots \cdots .$. ), and winter and autumn (October through March, - The horizontal lines reflect mean growth rate during each season and indicate the values used in the population model. per month. Data were classified by season (winter: January through March, spring: April through June, summer: July through September, autumn: October through December) and grouped into $20-\mathrm{mm}$ length classes for analysis.

Growth rates (in millimetres per month) during monthly intervals in spring and summer were significantly $>0$ (one-tailed $t$ test, $P<0.05$ for each month). Monthly growth rates in autumn and winter were not significantly $>0$ (one-tailed $t$ test, $P>0.2$ for each month), so spring and summer were considered to comprise a 6-mo growing season. When the effect of season was removed, body size (total length) had no significant effect on growth rate (ANOVA, $P=0.38$; Fig. 1 ). We estimated mean growth rate during spring to be 15.4 $\mathrm{mm} / \mathrm{mo}$ and during summer as $5.9 \mathrm{~mm} / \mathrm{mo}$ for fish of all sizes.

To translate growth rates into transition probabilities (given survival), we assumed a uniform distribution of

TABLE 2. Overwinter survival estimates for headwater stream salmonid eggs and fish. Estimates are for non-migratory brook trout unless otherwise indicated. The median value (right column) was used in the model.

\begin{tabular}{|c|c|c|c|}
\hline Stage & $\begin{array}{c}\text { Survival } \\
\text { estimate } \\
(\%)\end{array}$ & Source & $\begin{array}{l}\text { Model } \\
\text { value }\end{array}$ \\
\hline Eggs & $\begin{array}{l}79 \\
23 \\
1.3 \\
<79 \\
90-95\end{array}$ & $\begin{array}{l}\text { Brasch } 1949 \\
\text { Chapman } 1966^{*} \\
\text { Miller } 1970 \\
\text { Witzel and MacCrimmon } \\
\quad 1983 a, 1983 b^{\dagger} \\
\text { Elliott } 1984 \ddagger\end{array}$ & $70 \%$ \\
\hline Others & $\begin{array}{l}35-75 \text { age } 0-1 \\
24-57 \text { age } 1-2 \\
55 \\
43 \\
73 \\
55\end{array}$ & $\begin{array}{l}\text { Hunt } 1969 \\
\text { Brasch et al. } 1973 \\
\text { Elliott } 1987 \$ \S \\
\text { McFadden } 1961\end{array}$ & $55 \%$ \\
\hline
\end{tabular}

* Estimated for coho salmon.

+ Near $79 \%$ at optimal gravel size.

$\ddagger$ Estimated for brown trout.

$\S$ Assuming constant survival over the summer months. brook trout across sizes within each size class. We have no information about how sizes are actually distributed within a size class, but by using small size intervals $(10$ and $20 \mathrm{~mm})$, we decrease the impact of this assumption.

\section{Estimating overwinter survival $\left(\mathrm{w}_{0}\right.$ and $\left.\mathrm{w}\right)$}

Published estimates of survival from egg to emergence $\left(w_{0}\right)$ over a winter vary widely. Using estimates from studies on headwater populations of brook trout, coho salmon, and brown trout, we found a median $70 \%$ survival from egg to emergence (Table 2). Published values of overwinter survival in other age groups $(w)$ were slightly more consistent. Using estimates from studies of brook trout and brown trout, we found a median overwinter survival of $55 \%$ (Table 2).

\section{Estimating growing season survival rates (matrix $\mathbf{R}$ )}

We divided $\boldsymbol{R}(t, y)$, the matrix of transition rates due to survival, into two parts, a density-independent part for the general population and a density-dependent part for age-0 fish. In the following sections, we address each one separately.

Density-independent survival.-To estimate densityindependent survival we gathered survival data from the literature for large stream resident salmonids, which generally do not exhibit density-dependence in their survival (Allen 1969, Power 1980, Elliott 1987). Survival data are scarce for non-migratory stream salmonids $>1$ yr old, particularly data taken over time intervals shorter than a year. We found two such data sets (Table 3; McFadden 1961, Elliott 1987, 1989). We also used data from a migratory population of brown trout (Elliott 1985), but only from pre-migratory ages. For a fourth data set, we assumed an overwinter survival probability of 0.55 , and calculated a monthly summer survival rate from estimates of annual survival (McFadden et al. 1967). In these four data sets, we 
TABle 3. Density-independent survival estimated from individual cohorts of stream salmonids. The number of cohorts used in each estimate and the source of data are given for each data set used. Estimates are for non-migratory brook trout unless otherwise indicated.

\begin{tabular}{ccl}
\hline \hline Survival & $\begin{array}{c}\text { No. } \\
\text { cohorts }\end{array}$ & \multicolumn{1}{c}{ Source } \\
\hline 0.78 & 7 & McFadden 1961 \\
0.77 & 4 & McFadden et al. 1967* \\
0.92 & 16 & Elliott 1985† \\
0.825 & 2 & Elliott 1987, 1989‡ \\
\hline
\end{tabular}

* Calculated from annual survival rates, assuming overwinter survival of 0.55 .

$\dagger$ Pre-migratory ages of brown trout from a migratory population.

$\ddagger$ Age-1 fish from a non-migratory population of brown trout.

calculated proportion surviving over each time interval for each of the 29 cohorts sampled (Table 3). Per capita monthly survival was calculated as (final density/initial density) $)^{1 / t}$, where $t$ is the time interval (in months) between samples. From these, we calculated a mean monthly density-independent survival rate of 0.86 .

Density-dependent survival. - We have modeled survival as being density dependent in age-0 brook trout during their first growing season. Although the modeled population is classified by size rather than age, in practice, we kept account of the age- 0 cohort and only applied density-dependent survival probabilities to that cohort. In first-year stream salmonids, density-dependent survival is frequently expressed through downstream movement of individuals unable to feed (Chapman 1962, LeCren 1972, Elliott 1984b, Titus and Mosegaard 1991). This ultimately eliminates them from the population. Thus, we combined emigration and mortality into one general loss rate, which we refer to as mortality.

The way in which we formulate density-dependence in a population model and the way in which we estimate parameters for this function will likely have important consequences in the output of the model (Goodyear 1980). We have chosen to estimate survival as a function of density and body sizes in age- 0 fish, using an expression of "effective density," which is itself a function of fish size and number (Marschall and Crowder 1995). Effective density describes the potential of a particular cohort of fish in terms of food consumption rate. Clearly, this will be a function of both density and body size of the fish comprising the cohort. The effective density, $D(t)$, of a cohort of brook trout at time $t$ is

$$
D(t)=\sum_{t} n_{t}(t) \alpha m_{t}^{\beta},
$$

where $n_{t}(t)$ is the number of age- 0 fish in size class $i$ per area of stream and $\alpha m_{t}{ }^{\beta}$ is potential consumption by an individual in size class $i$ ( $m_{l}$ is average mass of an individual in size class $i$ ). Converting mass to total length, and using consumption parameters $(\alpha, \beta)$ estimated from Elliott (1975), we find

$$
D(t)=1.14 \sum_{t} n_{i}(t) l_{t}^{2.33},
$$

where $l_{t}$ is the total length midpoint of size class $i$ (derivation in Marschall and Crowder 1995).

Estimation of per capita survival of age-0 fish as a function of effective density $(D(t))$ requires data that include numbers and sizes of individuals at a particular site in a natural stream at the beginning of the growing season and at some time later in the same growing season. The same data set must include measurements at different initial densities, either over space or over years. We found three such data sets: Elliott's longterm data set for brown trout in Black Brows Beck, England (Elliott 1984a, b, 1985), LeCren's data for brown trout stocked as eggs at different densities at sites in Black Brows Beck (LeCren 1972), and Miller's data for brook trout at 12 sites in Hunt Creek, Michigan (Miller 1970). Elliott's and LeCren's length measurements (fork lengths [FL]) were converted to total lengths $(\mathrm{TL})$ using the relationship FL $\times 1.0326=\mathrm{TL}$ (Carlander 1969). From these data, per capita monthly survival, $r(t)$, was calculated as (final density/initial density) $)^{1 / u}$, where $u$ is the time interval (in months) between samples, and $D(t)$ was calculated from Eq. 2 for the start of each time interval for each cohort. All time intervals were between 0.9 and $1.15 \mathrm{mo}$. None of the data used to estimate density-dependence parameters were serially correlated; there was only one point used from any year for each location. We estimated parameters using both an exponential and a power form of the survival equation. Although the exponential form is in some ways more biologically satisfying at extreme levels of cohort density, we chose the power form of the function because it gave more acceptable patterns in the residuals over the range of actual observations. Using a non-linear least squares method we estimated parameters for the power form of the survival equation:

$$
\text { final density }=\text { initial density } \cdot c_{0}{ }^{u} \cdot D(t)^{c_{1} u} \text {. }
$$

Using the 36 measurements from three studies, we arrived at an expression for survival as a function of effective density:

$$
r(t)=\left(\frac{\text { final density }}{\text { initial density }}\right)^{1 / u}=16.9 D(t)^{-0789}
$$

Simultaneous estimation of $c_{0}$ and $c_{1}$ led to (1) correlation between the estimates of $c_{0}$ and $c_{1}$ and (2) existence of other pairs of $c_{0}$ and $c_{1}$ that differed greatly in value from the best-fit estimates, but differed little in the quality of their fit to the data. To ensure that we incorporated this uncertainty in best-fit parameters into our model, we generated a set of five pairs of values of $c_{0}$ and $c_{1}$ to be used in the model. We calculated the sums of squares for combinations of values of $\left(c_{0}, c_{1}\right)$ spanning the $95 \%$ confidence intervals for each of the 
TABLE 4. Reproductive measures used to estimate average number of eggs per fish in each size class. In the first seven classes, $\%$ mature $=0$, so we have omitted these. Values of percentage female, percentage of females that are mature, and fecundity (number of eggs per mature female) for each size class are means of values from all data sets. Mean number of eggs per individual brook trout in each size class is calculated as $(\%$ females $/ 100) \times(\%$ mature females/100 $)$ $\times$ fecundity.

\begin{tabular}{|c|c|c|c|c|}
\hline $\begin{array}{l}\text { Size class } \\
\text { midpoint } \\
(\mathrm{mm})\end{array}$ & $\begin{array}{c}\mathrm{Fe}- \\
\text { males } \dagger \neq \S \| \\
(\%)\end{array}$ & $\begin{array}{c}\text { Mature } \\
\text { females* }{ }^{*} \dagger \neq \| \\
(\%)\end{array}$ & $\begin{array}{c}\text { Fecun- } \\
\text { dity* } \dagger \neq \S I \\
\text { (No. eggs } \\
\text { per mature } \\
\text { female) }\end{array}$ & $\begin{array}{l}\text { No. eggs } \\
\text { per fish }\end{array}$ \\
\hline$<95$ & 50 & 0 & 0 & 0 \\
\hline 112.5 & 50 & 40 & 68 & 14 \\
\hline 130 & 50 & 66 & 106 & 35 \\
\hline 150 & 50 & 78 & 152 & 59 \\
\hline 170 & 50 & 90 & 207 & 93 \\
\hline 190 & 50 & 96 & 272 & 131 \\
\hline 210 & 50 & 99 & 348 & 172 \\
\hline 230 & 50 & 100 & 434 & 217 \\
\hline
\end{tabular}

* Cooper 1953 .

$\dagger$ McFadden 1961.

\$ Wydoski and Cooper 1966 .

§ Lennon 1967.

\| McFadden et al. 1967.

II Gibson et al. 1976.

two parameters. Our set of five pairs of values included the best-fit pair $(16.9,-0.789)$, the extremes of the $95 \%$ confidence intervals of the estimates $([3.6,-0.66]$ and $[30.3,-0.91])$, and a pair in either direction along the axis perpendicular to the axis running through the extremes and with the same sum of squares ([18, $-0.77]$ and $[15,-0.81])$. These pairs of values had sums of squares that ranged from 141 (best-fit) to 200, so clearly, they described the data comparably well. We repeated each population model run and output analysis using each of these five pairs of parameters to ensure we captured some portion of the uncertainty associated with estimates of this important aspect of the life history.

\section{Estimating fecundity (vector $\mathbf{b}$ )}

Average fecundity per individual of size $i$ was estimated as the product of number of eggs per mature female of size $i$, proportion of size $i$ females that are sexually mature, and proportion of size $i$ individuals that are female. To estimate each of these three sets of parameters, we used data from studies of stream resident native brook trout (Table 4; Cooper 1953, McFadden 1961, Wydoski and Cooper 1966, Lennon 1967, McFadden et al. 1967, Gibson et al. 1976). Percentagefemale estimates from the literature range from 20 to $83 \%$, having no consistent relationship with age, so we assumed a 50:50 sex ratio at all sizes. For each size class, we calculated an average value of percentage mature females from four data sets and number of eggs per mature female from five data sets (Table 4). Overestimates of fecundity were avoided by only using egg counts taken immediately before spawning. To calcu- late the average number of eggs per fish in each size class, we first calculated the mean values of average eggs per mature female and average percentage mature females over all data sets for each size class used in the population model. The product of these two values and the average proportion female (sex ratio) gave an average number of eggs produced per individual brook trout in each size class per year (Table 4).

\section{Sensitivity}

We have assessed the sensitivity of this model to parameter perturbations in several ways. First, we measured sensitivity to standard size-specific changes in growth and density-independent survival rates. Next, we assessed population response to a full factorial design of parameter perturbations that would be associated with interactions with rainbow trout. And finally, we asked what magnitude of perturbations of suites of parameters associated with each ecological pressure are necessary to cause local extinctions. In the Discussion, we compare the magnitude of perturbations used in the sensitivity analysis to the magnitude seen in actual studies of brook trout populations under...various environmental pressures.

Each simulation was run until the population reached a relatively stable size distribution. Because of the density dependence included in the model, the population came to a stationary size distribution (i.e., an equilibrium population size and size distribution). We considered the population to be at equilibrium when $\lambda$, the ratio of population sizes between two consecutive years, was $<1.00001$ but $>0.99999$. We explored a number of initial conditions to ensure the model produced only one stationary state under biologically reasonable conditions. Given starting size distributions of (1) 5000 fish in the smallest size class in spring with no fish in other size classes, (2) 100 fish in each size class in spring, and (3) a distribution closer to those observed in nature, we found no tendency for the modeled population to settle at more than one stationary state under a given set of parameters. In addition, we found no evidence that the stationary state was anything other than a stationary point (e.g., we never observed any two-point cycles).

Growth and survival.-Because the different ecological pressures (i.e., species introduction, habitat alteration, and harvesting) affect growth and survival at different parts of the brook trout life history, we have assessed sensitivity of the modeled population to changes in growth and density-independent survival at different life stages. Growth rate (in millimetres per month) was increased and decreased by $10 \%$ independently in each of five groupings of size classes (20 59, 60-99, 100-139, 140-179, and 180-239 mm). For each perturbation of the growth parameters, we recorded three population responses: equilibrium population size, the number of large fish in the population, and the proportion of the population consisting of large 
fish. We arbitrarily set the lower limit of large fish to be $140 \mathrm{~mm}$, which is slightly smaller than the minimum legal size in a commonly used harvesting regulation. For each of the five size classes, sensitivity $(S)$ of each of the three population responses $(Y)$ to changes in growth rate $\left(g_{j}\right)$ of size class grouping $j$ was calculated by:

$$
S\left(g_{\jmath}\right)=\frac{Y\left(1.1 g_{j}\right)-Y\left(0.9 g_{\jmath}\right)}{Y\left(g_{j}\right)} .
$$

This measures the magnitude of the change in population response brought on by an increase and decrease in parameter value, as a proportion of the original population response. A value of 0 in $S\left(g_{j}\right)$ indicates that this particular population response is insensitive to changes in this particular parameter. The larger the deviation from 0 (in either direction), the higher the sensitivity of the response to changes in parameter values.

This analysis was repeated for density-independent survival rates, again measuring sensitivity of the three population responses to $10 \%$ changes in survival rates at different size class groupings, including the egg-tolarval transition. In age-0 fish, which experience density-dependent survival in the model, changing the density-independent survival rate in this sensitivity analysis meant changing their overall survival rather than changing the way density affected their survival.

Rainbow trout effect.-Because the presence of another species, such as rainbow trout, has potential effects on several very different aspects of the life history of brook trout (Table 1), we assessed the relative importance of these effects and their interactions by a factorial design of model runs, varying four parameters at two levels each. Adult growth rate (size classes 915 , i.e., fish $\geq 100 \mathrm{~mm}$ ), small fish growth rate (size classes $1-4$, i.e., fish $<60 \mathrm{~mm}$ ), small fish survival rate, and $c_{1}$, the slope of density dependence in age- 0 survival rate, were each varied at 0.9 and 1.1 times the original parameter. As in the growth and survival sensitivity analysis, three population responses to these changes in parameters were measured: equilibrium population size, number of large fish in the population, and proportion of large fish in the population. The potentially interacting effects of the four parameters were measured using Yates' algorithm (Box et al. 1978). We used an ANOVA to measure the statistical significance of the main effects and their interactions. This analysis differs from the previous growth and survival sensitivity analysis by (1) varying growth rate of all sizes of adults at once, (2) varying growth rate and densityindependent survival rate (i.e., overall survival rate rather than the way in which density affects survival rate) of only the smallest brook trout, (3) varying density-dependent survival, and (4) completing the full factorial of parameter perturbations to look at interactions of effects.

Local extinctions. - Although some of the ecological pressures addressed in this study may be sublethal to an individual brook trout, as they cause changes in the size structure of the population and the fecundity and proportion of reproducing individuals present they may cause local extinctions. We have taken the combinations of vital rate responses to each of the ecological pressures (Table 1) and asked how large the responses must be to cause a local extinction of the modeled brook trout population.

To look at the effect of species introduction (rainbow trout) we varied, in concert, small-fish survival (classes $1-4 ; 20-60 \mathrm{~mm}$ ), growth rates of all fish, and slope of the density-dependent function of small-fish survival (see Table 1). We simulated siltation effects by varying egg-to-larva survival rate. To assess the effect of acidity, we simultaneously varied small-fish survival (classes 1-4; 20-60 mm), survival of eggs to larvae, and growth rates of all fish. Effect of harvesting was simulated by varying large-fish (classes 11-15; >140 $\mathrm{mm}$ ) survival rate.

To assess levels of changes necessary to bring about local extinctions, we changed, by $10 \%$ increments, the values of the suite of parameters associated with each ecological pressure (Table 1) until the equilibrium population size was zero. Because a decrease in the slope of density dependence $\left(c_{1}\right)$ would result in an increase in survival while decreases in the other parameters are generally associated with decreases in survival, we changed $c_{1}$ by the inverse of the factor we used for the other parameters.

\section{RESULTS}

The population resulting from the original parameters, before sensitivity perturbations, did not differ markedly from size distributions of natural southern Appalachian brook trout populations (Fig. 2). In this comparison, we used only size distribution data that had not been used in estimating parameters in the model.

\section{Growth and survival}

The modeled population was most sensitive to changes in growth rates when these changes occurred in small fish (Fig. 3). Although equilibrium population size was relatively robust to changes in growth rates, it was most affected by those changes that involved small fish (Fig. 3a). When growth rates of the smallest fish were increased, the population size actually decreased slightly. The size distribution of the population, however, was more sensitive to changes in growth rate. Numbers of large fish ( $\geq 140 \mathrm{~mm}$ ) and proportion of large fish both were quite sensitive to changes in growth rate of age- 0 fish $(\leq 100 \mathrm{~mm}$; Fig. $3 \mathrm{~b}, \mathrm{c})$. As growth rates of age- 0 fish were increased, the number and proportion of large fish in the equilibrium population increased.

Population responses to changes in density-independent survival rates were strongest when these changes occurred in intermediate-to-large fish survival (Fig. 4). 

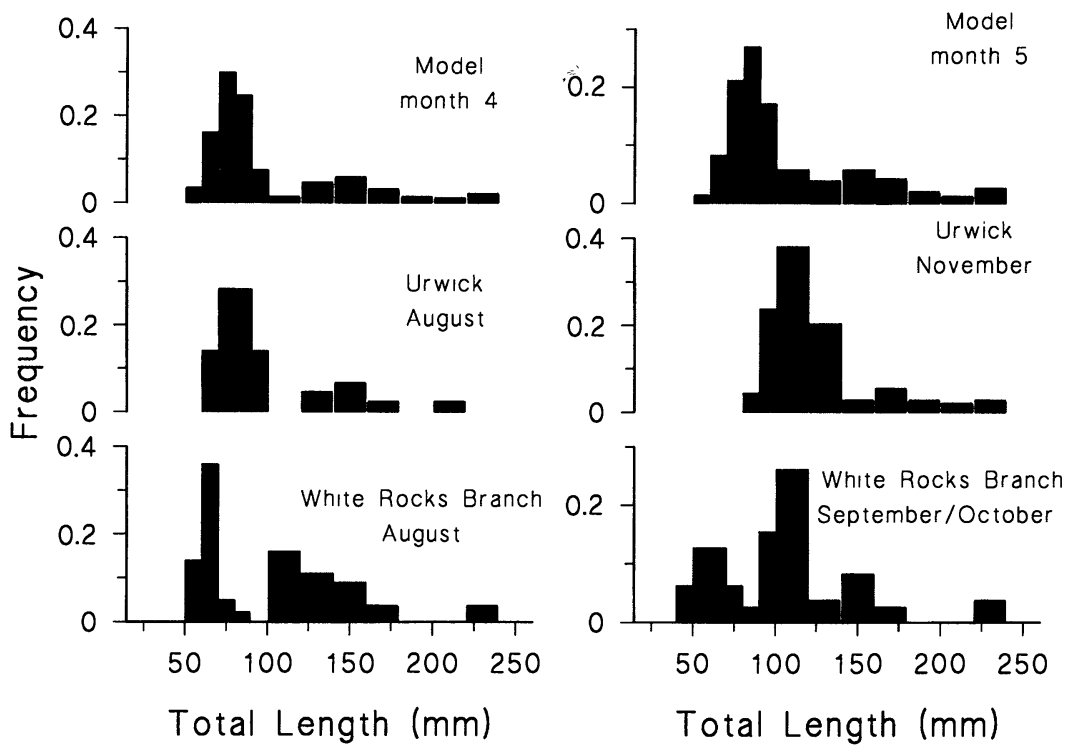

FIG. 2. Size frequency distribution of the modeled brook trout population and two natural populations during (left panels) late summer and (right panels) late fall. Data for the two natural populations came from (1) a survey of a North Carolina stream (Urwick 1986) and (2) a 1989 survey of White Rocks Branch, Giles County, Virginia (E. A. Marschall, unpublished data). Note that the relative widths of the bars on the graph reflect the relative widths of the modeled size classes.

The modeled population was relatively insensitive to changes in survival of eggs to larvae and of the smallest size classes. Although equilibrium population size was relatively robust to changes in survival rates of most size classes, it was quite sensitive to changes in survival of fish in classes 5-8 (60-100 mm; Fig. 4a). This roughly corresponds to brook trout late in their first growing season and early in their second growing season. An increase in survival of these fish resulted in an increase in equilibrium population size. Both measures of size distribution (numbers and proportion of large fish) were very sensitive to changes in large fish survival rates (Fig. 4b, c), with increases in large-fish survival resulting in more large fish in the equilibrium population.

\section{Rainbow trout effect}

In a factorial design of model runs, we treated the multiple possible effects of rainbow trout on growth and survival of brook trout at different life stages. ANOVA results indicated that both small-fish growth rate and the slope of the density-dependent survival function had significant effects on all three population responses (population size, number of large fish, and proportion of large fish). In addition, small-fish survival had a significant effect on population size and proportion of large fish, whereas large-fish growth rate had a significant effect on both measures of size structure. Overall, population size was significantly affected by the three small-fish main effects (growth, survival, and density-dependent survival) but not by large-fish growth rate. Although the two measures of size structure were also significantly affected by small-fish growth and density-dependent survival, they were also significantly affected by large-fish growth rate. In addition to the main effects, interactions between smallfish growth and both small-fish survival and large-fish growth significantly affected proportion of large fish, though the magnitude of these interactive effects was not great.

Although we found many significant effects, the vast majority of the variance was explained by only a few of the factors. Using Yates' algorithm (Box et al. 1978), we ranked the factors according to the magnitude of their effect on the population response variables and identified those significant effects that had the greatest impact. Mean population size and number of large fish both changed most dramatically when slope of the density-dependent survival function was increased and decreased by $10 \%$. The only other factor to cause a change of at least $5 \%$ in these two responses was small-fish growth rate. Small-fish growth rate also was the only factor to have an effect of at least $5 \%$ on proportion of large fish. Although an increase in small-fish growth rate caused a decrease in equilibrium population size, it resulted in greater numbers (and proportion) of large fish in the population.

\section{Local extinctions}

Local extinctions in the modeled population occurred at relatively severe to moderate reductions in those vital rates associated with responses to acidity and species introduction (Table $1 ; \approx 0.3$ of original parameters; Fig. 5). In contrast, we simulated harvesting at a level that decreased large-fish survival to 0.01 of its original value, and the population still maintained 

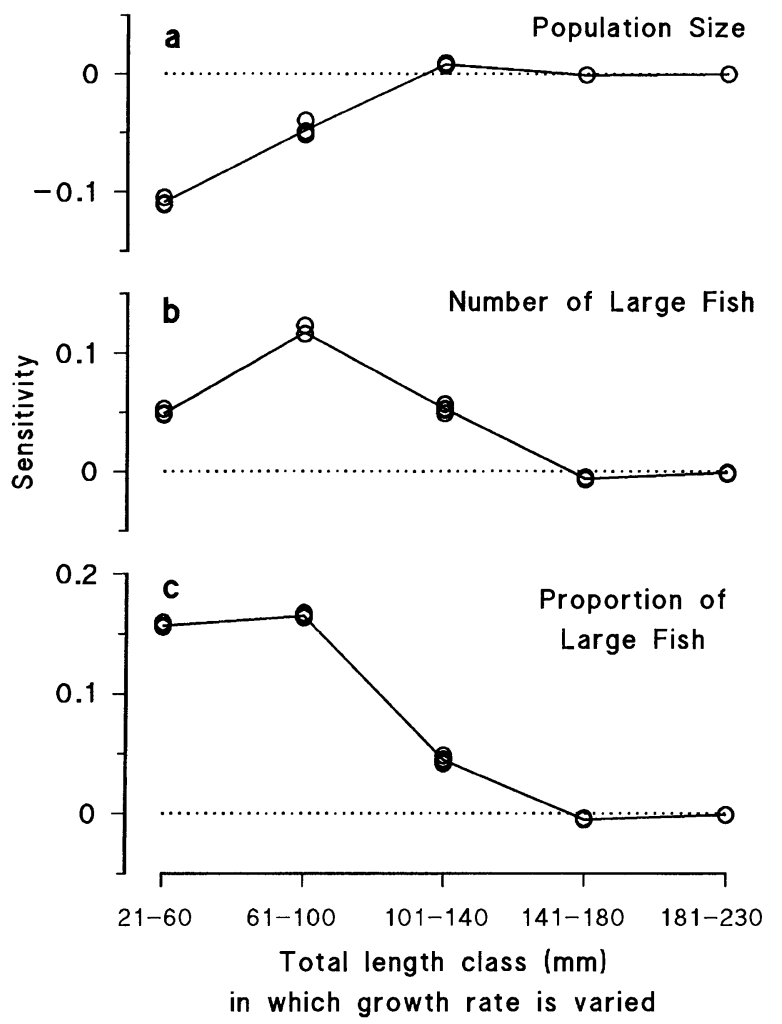

FIG. 3. Sensitivity of three population responses to perturbations of growth parameters in individual size class groupings (all other parameters held constant). (a) Sensitivity of equilibrium population size. (b) Sensitivity of number of fish $\geq 140 \mathrm{~mm}$ in equilibrium population. (c) Sensitivity of proportion of fish $\geq 140 \mathrm{~mm}$ in equilibrium population. For each length class, we have plotted a point for each of five pairs of values of $c_{0}$ and $c_{1}$ (density-dependence parameters, see Methods).

a positive equilibrium. Even with very high harvesting rates of large fish, the population size changed little, though the population size structure changed dramatically. The population was also maintained when we simulated siltation at levels that severely decreased egg survival; local extinction did not occur until egg survival rates were $<0.05$ of their original value. The modeled population appeared relatively robust to egg loss.

We looked more closely at the effect of acidity by plotting the three population measures (size, number of large fish, and proportion of large fish) against the size of the perturbations to the parameter values (Fig. 5 ). We found that both number and proportion of large fish declined steadily with a decline in parameter values, but population size actually increased at low levels of decrease in parameter values (Fig. 5) before decreasing quickly to extinction. Consequently, we consider number and proportion of large fish to be a better early forecaster of local extinction than population size. Population size was relatively insensitive to changes in parameters associated with acidity over a wide range of parameter values until the values reached a low
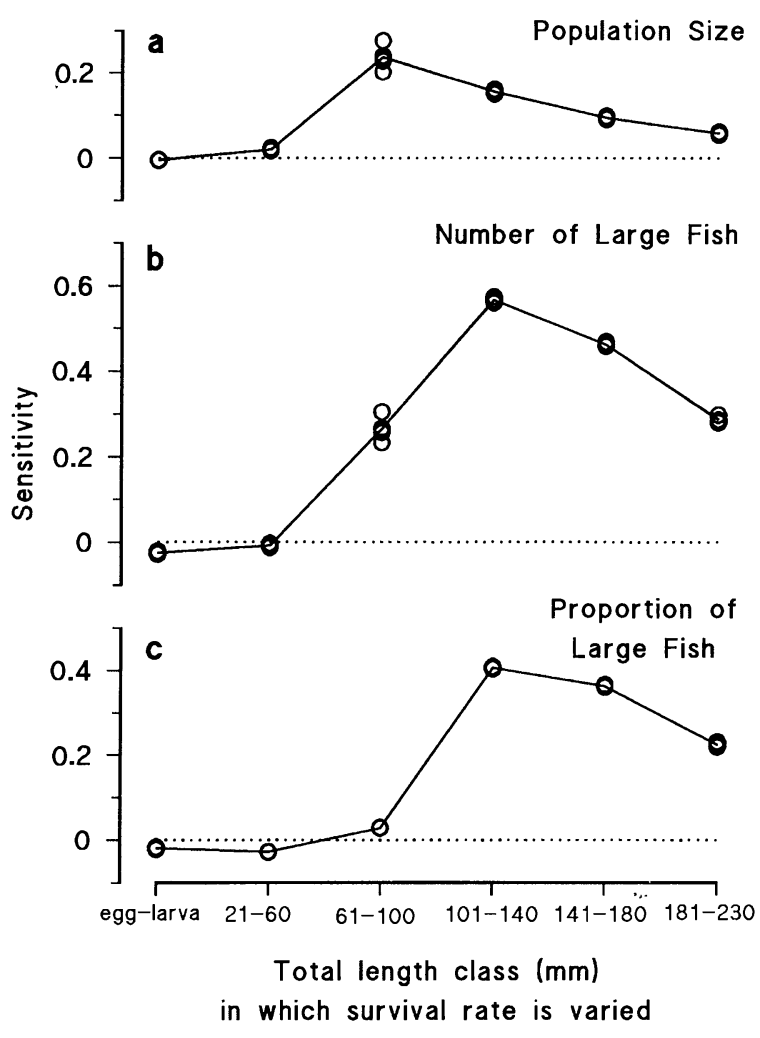

FIG. 4. Sensitivity of three population responses to perturbations of survival parameters in individual size class groupings (all other parameters held constant). (a) Sensitivity of equilibrium population size. (b) Sensitivity of number of fish $\geq 140 \mathrm{~mm}$ in equilibrium population. (c) Sensitivity of proportion of fish $\geq 140 \mathrm{~mm}$ in equilibrium population. For each length class, we have plotted a point for each of five pairs of values of $c_{0}$ and $c_{1}$ (density-dependence parameters, see Methods).

enough level to cause the population to crash (Fig. 5a). In contrast, proportion of large fish decreased steadily as values of parameters decreased (Fig. 5c). Both proportion and number of large fish decreased to $\approx 50 \%$ of their original values when we decreased parameters to $\approx 0.6$ of their original values.

\section{Density-dependent survival}

We ran each of the simulations using each of five sets of density-dependent survival parameters. Although different sets of parameters often yielded different results in terms of absolute population size or number of large fish, the results of sensitivity and local extinction analyses did not differ between different sets of these parameters.

\section{DisCUSSION}

Because there have been a number of concurrent anthropogenic effects on southern Appalachian headwater populations of brook trout, we assessed how populations respond to each effect to understand the recent history and possible future course of these populations. 


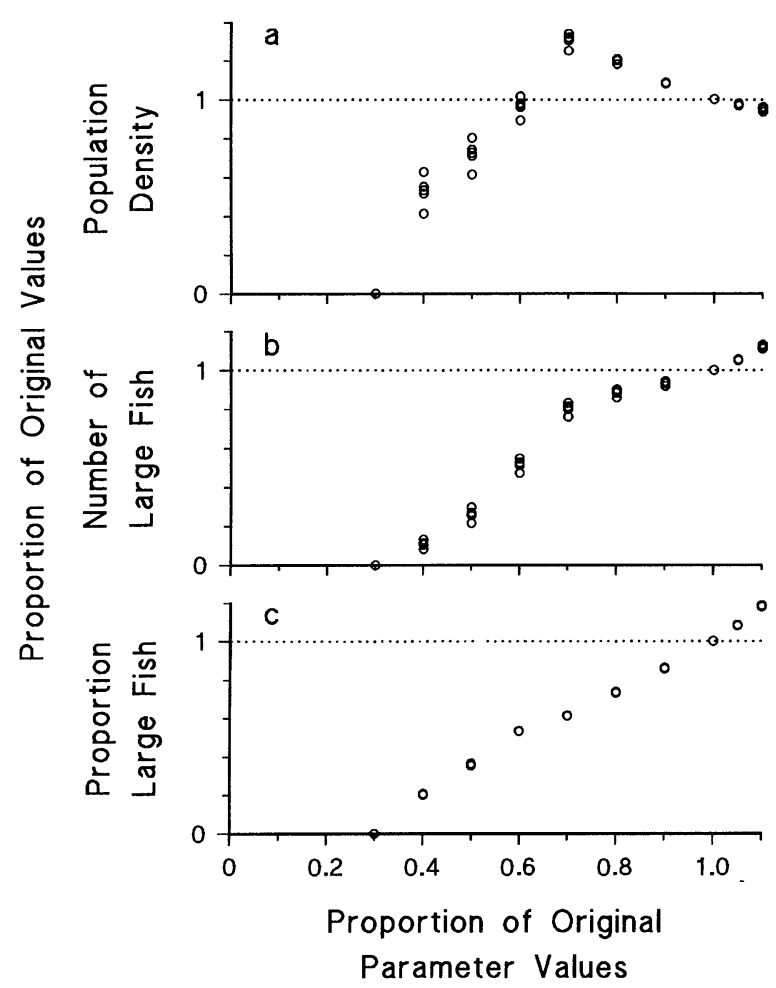

FIG. 5. Response of the modeled brook trout population to perturbations in suites of parameters associated with the effect of acidity on vital rates. (a) Equilibrium population size. Local extinction occurs when equilibrium population size falls to zero. (b) Number of large fish in the equilibrium population. (c) Proportion large fish in the equilibrium population.

When the potential growth and survival responses to these anthropogenic effects were separated and the population response to these changes in vital rates projected, we found that population size was not very sensitive to changes that affected growth rate, but was sensitive to changes that affected survival rate in large juvenile and sub-adult $(60-100 \mathrm{~mm})$ brook trout (Figs. 3 and 4). These size classes of fish are too small to be affected by sport harvest and too large to be susceptible to the direct mortality effects of predation or acidity. So although population size is most sensitive to survival of these size classes, these size classes are the least likely to respond to anthropogenic effects with a decrease in survival.

This pattern of highest sensitivity to survival of intermediate size or stage classes has been observed in other species. Hartshorn (1975) saw this result in a sizeclassified model of a tropical canopy tree (Pentaclethra macroloba). He found that the population growth rate was most sensitive to survival of the immediately prereproductive size class (Hartshorn 1975). Crouse et al. (1987) observed this pattern in a model of sea turtles (Caretta caretta). Although the sensitivity pattern was the same, the biological importance of it is much great- er in the sea turtle than in the brook trout because human impacts on the sea turtle involve mortality of these intermediate stages (via shrimp trawling; Crouse et al. 1987). Use of turtle excluder devices that reduce mortality rates of large juveniles, sub-adult and adult loggerhead sea turtles should have positive effects on population recovery (Crowder et al. 1994). Whereas density-dependent survival was an important part of the brook trout model, neither the canopy trees nor the sea turtles were modeled with density-dependent survival. In these previous studies without density dependence, investigators have measured changes in equilibrium population growth rate rather than changes in equilibrium population size. Clearly the link between population growth rate and population size makes these two measures analogous in these different systems. The similarity in pattern of sensitivity exists despite the differences underlying the models of these populations.

The generality of the pattern of population sensitivity to size-specific (or age-specific) changes in survival among vastly different types of organisms may reflect the generality of patterns in reproductive value. Increases in mortality rate should have the strongest impact on the population's ability to replace itself when those increases occur in stages with high relative reproductive value (Slobodkin 1968, Law and Grey 1988). Traditionally, reproductive value is considered to peak near the age of first reproduction. Although we did not estimate reproductive value in this modeled brook trout population, if it follows the pattern generally assumed in other organisms, then it may lead to sensitivity of the population to changes in survival of size classes 5-8 and 9-10, as seen here. Size-dependent reproductive value would be an appropriate population attribute to measure in concert with size structure of the population (Caswell 1982). Knowledge of reproductive value would allow predictions of which stages, when perturbed, will be most important in determining population dynamics or persistence. In addition, changes in size-dependent patterns of reproductive value may reflect significant changes in life history patterns under different environmental conditions.

\section{Local extinctions}

In assessing the strength of response in vital rates necessary to bring about a local extinction of a population, we found that rainbow trout and acidity had severe effects at relatively moderate perturbations of the vital rates. Before accepting that these are the anthropogenic effects with the greatest potential for detrimental impact, we must first ask how these levels of perturbations compare to the level of responses we expect based on observed responses to these environmental factors (Dunham 1993).

Acidity.-Results of laboratory experiments measuring brook trout response to $\mathrm{pH}$ showed that egg-tolarva survival at pH 5.2 was 0.69 of survival at pH 6.5 (Ingersoll et al. 1990). At pH near 5, survival of age- 
0 fish was $0.88-1.0$ and growth rate of age-0 fish was $0.6-0.7$ of the values at $\mathrm{pH}$ near 6.5 (Ingersoll et al. 1990, Marschall 1991). For adult fish, this change in $\mathrm{pH}$ did not affect survival, though it caused growth rates to be $0.5-0.8$ of the $\mathrm{pH} 6.5$ growth rates (Mount et al. 1988, Marschall 1991). Although these vital rate responses are above the $\approx 0.3$ response we suggest would be necessary for local extinction (Fig. 5), they encompass a range over which we predict $50 \%$ reductions in number and proportion of large fish and a sudden decline in total population size (Fig. 5).

Rainbow trout.-Although much research has been done on brook trout behavior (Helfrich et al. 1982, Cunjak and Green 1984), diet (Johnson 1981, Larson and Moore 1985), and habitat use (Cunjak and Green 1983, Rose 1986, Lohr and West 1992) in response to presence of rainbow trout, there is much less information about vital rate responses to this introduced species. In field enclosure experiments, we observed a growth rate response of large age- 0 brook trout $(>55$ $\mathrm{mm}$ ) to presence of large rainbow trout, but no survival response over $\approx 4$-wk experiments (Marschall 1991). Brook trout growth rates in the presence of large rainbow trout were 0.8 times their growth rates in the absence of rainbow trout. But, we have no estimates of growth rate effects for smaller or larger brook trout, nor do we have any estimates of density-dependent survival response. Again, this measured effect is not as severe as the $\approx 0.3$ response we suggest would be necessary for local extinction, but a response of this magnitude over all the relevant parameters would be sufficient to cause a $50 \%$ reduction in the modeled population size.

Siltation.-Witzel and MacCrimmon (1983a) showed egg hatching success in small-grained substrate to be 0.13 of hatching success in coarser grained substrate. According to our analysis, a value slightly lower than this could potentially lead to local extinction. Admittedly, less severe alterations of the substrate would have less severe impacts on hatching success (Witzel and MacCrimmon 1983a), but the data and model certainly give cause for concern.

Harvesting.-To compare model perturbations of adult mortality rate as affected by harvesting to estimates from natural populations would require some comparison of mortality rates from fished and unfished streams. No such data are available.

The differences in impact of these different anthropogenic effects appear to be a result of their effects on different parts of the life history. Because these fish can reproduce at fairly small sizes, an appropriate minimum size limit in the fishery should allow the model population to maintain itself. And, because age- 0 brook trout survival is treated in the model as density-dependent, decreasing density at the egg-to-larval stage should have a much reduced impact. Therefore, the ecological pressures (Table 1) that affect the life history at these stages should have relatively smaller impact.
It is important to note that these results illustrate the way in which density dependence can drive both model results and population dynamics. Because of this, the way in which we represent density dependence in the model becomes very important (Goodyear 1980). This density-dependent relationship between numbers of adults and number of progeny produced is at the heart of an immense body of research in fisheries biology (Ricker 1954). We certainly have not exhausted the outcomes possible under different scenarios of densitydependence or different methods in estimating densitydependent parameters in our model. Given different formulation of these processes, the model may produce different predictions about local extinctions.

In addition to anthropogenic effects affecting different parts of the life history, they also affect different extents of the life history. The ability of a population to maintain itself in the face of each of many anthropogenic effects does not imply that it will be able to maintain itself in the face of a combination of these separate pressures. Some factors (e.g., harvesting and siltation) affect only one stage, whereas others (e.g., $\mathrm{pH}$ and rainbow trout) affect many stages. Even if effects at all stages were equally important, those factors that negatively affect brook trout at many stages of the life cycle have more potential for impact than those that affect them at only one stage. Combining effects on many stages with effects on key stages adds to the potential impact of $\mathrm{pH}$ and rainbow trout in relation to siltation and harvesting.

Although the factorial design of model perturbations in this study allowed us to assess how changes in growth and survival at different stages interacted to produce population level responses, this modeling study does not allow examination of how combinations of anthropogenic effects might interact to affect growth and survival. The importance of this problem has been recognized and generally addressed through surveys of streams and stream communities. Surveys correlating species presence/absence with a number of abiotic and biotic variables are a start toward understanding how ecological factors interrelate to affect trout populations (e.g., Burton and Odum 1945, Fausch 1989), but manipulative experiments will be necessary to untangle the effects of correlated environmental conditions. For example, although we could use the model to predict the population responses to interactions of growth and survival effects for $\mathrm{pH}$ and rainbow trout, the model will not help in determining whether $\mathrm{pH}$ and rainbow trout themselves interact in their effect on growth and survival. Both $\mathrm{pH}$ and probability of spatial overlap with rainbow trout increase from upstream to downstream. Ultimately, we need to know, for example, whether brook trout growth and survival responses to rainbow trout under low $\mathrm{pH}$ conditions differ from the response under other environmental conditions. Although $\mathrm{pH}$ has a negative impact on brook trout, its impact is even greater on rainbow trout, so predicting 
how $\mathrm{pH}$ and rainbow trout will interact to affect brook trout growth and survival will require experiments designed explicitly for this purpose.

Although population size in this modeled brook trout population may be fairly insensitive to changes in survival rate in many size classes, it appears to be the population size structure, rather than the population size per se, that determines a population's resiliency to perturbation. Population size is relatively robust to changes in vital rates because the population is dominated numerically by fish in the youngest age class, and this number is determined through density-dependent processes. Because of this, major effects on population size will not be seen until the adults can no longer produce an excess of age-0 fish. Although the capacity of the reproducing adults to produce offspring will decline steadily as number of adults in the population declines, it will not be reflected in the population size until the population becomes dangerously small. So the decrease in numbers of large fish that accompany many of these ecological pressures gives more information about the population's ability to withstand future perturbations than does information about population size. Ultimately, the local extinction resulting from acidity and rainbow trout effects on vital rates came through detrimental changes in size structure by reducing the number of reproducing individuals (Fig. 5).

It is important to recall that this is a deterministic model. With this model, we can ask how general changes in growth and survival at different stages will affect the population. We need to recognize, however, that in these stream systems, a poorly timed flood or drought can wipe out most of a year class. When we combine these randomly occurring disasters with brook trout populations having extreme size distributions (in response to some other anthropogenic effect), we may find a much higher risk of local extinction than that suggested by analysis of the strictly deterministic model. Given that brook trout populations occur in systems in which annual environmental fluctuations make this loss of a year class a real possibility, one must take this into consideration when interpreting the results.

\section{Management Conclusions}

We have assessed the potential brook trout responses to species introduction (rainbow trout), habitat alteration (sedimentation and increased acidity), and harvesting. Of these, species introduction and acidity had the greatest negative impact on the modeled population. The magnitude of perturbations to life history parameters necessary to cause drastic changes in population size and size structure were within the range of observed individual responses to acidity. In addition, siltation has a potentially strong negative impact on eggto-larval survival; when this is the case, it can also have a strong negative impact on the population as a whole. But the population was able to maintain itself even in the face of fairly low egg-to-larva survival. And finally, with an appropriate minimum size limit, the modeled population could be maintained even under severe fishing pressure. We must express caution, however, in interpreting these results without considering effects of stochastic environmental variation. Particularly with effects of siltation and harvesting, the population size structure may be changed drastically. Consequently, the population may have little buffer against even a short run of bad years (e.g., years of drought or poorly timed floods).

We have done this quantitative local extinction analysis to ask whether the growth and survival responses of the magnitude we actually observed in nature are in the range of those that might cause local extinction in the modeled population. We do not, however, believe we have predicted the precise level of response that will bring about local extinctions. Rather, this analysis should help assess relative impact of different anthropogenic pressures.

Some general patterns arose from extinction and sensitivity analyses. Because these fish can reproduce at a small size, negative impacts on survival of the largest fish were not detrimental to the persistence of the population. Because survival of small juveniles is density dependent, even moderately sized perturbations to survival in this stage had little effect on the ultimate population size. Because of this importance of density dependence, we need to further evaluate this process in the model. In general, a brook trout population will respond most negatively to factors that decrease survival of large juveniles and small adults and to factors that decrease growth rates of small juveniles. These generalizations give us a starting point from which to assess potential impacts of other anthropogenic effects. We recognize that each stream and each population is different and that we could not possibly predict population size in all streams from such a general model. However, we have chosen factors that have changed over a wide geographic region in many streams to help us understand a general, wide-ranging decline in brook trout distribution. We are not attempting to make quantitative predictions of population sizes or size structures. Instead, we are trying to predict which factors will cause the most important changes in population size and size structure.

This case study demonstrates a multifactor approach to modeling population responses to multiple anthropogenic factors. Because society has limited resources to aid species recovery for species like brook trout that have declined in abundance and also in spatial distribution, we need an approach that will allow us to compare the relative effects of various factors on population growth rates. Some possible management scenarios may address relatively sensitive vital rates while the population may be unresponsive to other management approaches. Our approach should help identify which mechanisms contributed most to population declines 
and which mitigation measures might contribute most to population recovery.

\section{ACKNOWLEDGMENTS}

This work was supported by the Lucas Fellowship in Biomathematics at North Carolina State University (to E. A. Marschall), the J. F. Allen Award from the American Fisheries Society (to E. A. Marschall), an Electric Power Research Institute Fellowship in Population Dynamics (to E. A. Marschall), a U.S. Forest Service Cost-Share Agreement (to L. B. Crowder and E. A. Marschall), the Department of Zoology at North Carolina State University (to L. B. Crowder), and the Department of Zoology at The Ohio State University (to E. A. Marschall). R. Wright, L. Real, B. Letcher, and S. Heppell provided helpful discussions during this work. S. Christensen, $\mathrm{X}$. He, and S. Carpenter provided invaluable suggestions on the model and manuscript.

\section{Literature Cited}

Allen, K. R. 1969. Limitations on production in salmonid populations in streams. Pages 3-18 in T. G. Northcote, editor. Symposium on salmon and trout in streams. Institute of Fisheries, University of British Columbia, Vancouver, British Columbia, Canada.

Anonymous. 1982. 1980 National survey of fishing, hunting, and wildlife-associated recreation. U.S. Department of the Interior and U.S. Department of Commerce. U.S. Government Printing Office, Washington, D.C., USA.

1985. Analysis of the 1985 national survey of fishing, hunting, and wildlife-associated recreation: trout fishing in the U.S. U.S. Department of the Interior Report 856. U.S. Government Printing Office, Washington, D.C., USA.

Bergman, H. L., and J. S. Mattice. 1990. Lake acidification and fisheries project: early life stage and juvenile brook trout (Salvelinus fontinalis). Canadian Journal of Fisheries and Aquatic Sciences 47:1578-1579.

Bergman, H. L., J. S. Mattice, and D. J. A. Brown. 1988. Lake acidification and fisheries project: adult brook trout (Salvelinus fontinalis). Canadian Journal of Fisheries and Aquatic Sciences 45:1561-1562.

Bierzychudek, P. 1982. The demography of Jack-in-the-pulpit, a forest perennial that changes sex. Ecological Monographs 52:335-351.

Box, G. E. P., W. G. Hunter, and J. S. Hunter. 1978. Statistics for experimenters. John Wiley and Sons, New York, New York, USA.

Brasch, J. 1949. Notes on natural reproduction of the eastern brook trout ( $S$. fontinalis) with a preliminary report of several experiments on the subject. Wisconsin Conservation Department, Division of Fishery Biology, Investigational Report Number 653, Madison, Wisconsin, USA.

Brasch, J., J. McFadden, and S. Kmiotek. 1973. Brook trout: life history, ecology, and management. Wisconsin Department of Natural Resources Publication 226, Madison, Wisconsin, USA.

Burns, B. R., and J. Ogden. 1985. The demography of the temperate mangrove [Avicennia marina (Forsk.) Vierh.] at its southern limit in New Zealand. Australian Journal of Ecology 10:125-133.

Burton, G. W., and E. P. Odum. 1945. The distribution of stream fish in the vicinity of Mountain Lake, Virginia. Ecology 26:182-194.

Carlander, K. D. 1969. Handbook of freshwater fishery biology, Volume 1. Iowa State University Press, Ames, Iowa, USA.

Caswell, H. 1982. Stable population structure and reproductive value for populations with complex life cycles. Ecology 63:1223-1231.
1989. Matrix population models. Sinauer Associates, Sunderland, Massachusetts, USA.

Caswell, H., and A. M. John. 1992. From the individual to the population in demographic models. Pages 36-66 in D. L. DeAngelis and L. J. Gross, editors. Individual-based models and approaches in ecology: populations, communities and ecosystems. Routledge, Chapman and Hall, New York, New York, USA.

Chapman, D. W. 1962. Aggressive behavior of juvenile coho salmon as a cause of emigration. Canadian Journal of Fisheries and Aquatic Sciences 19:1047-1080.

1966. Food and space as regulators of salmonid populations in streams. American Naturalist 100:345-357.

Cooper, E. L. 1953. Periodicity of growth and changes of condition of brook trout (Salvelinus fontinalis) in three Michigan trout streams. Copeia 2:107-114.

Cosby, J. B., P. F. Ryan, J. R. Webb, G. Hornberger, and J. N. Galloway. 1991. Mountains of Western Virginia. Pages 297-318 in D. F. Charles, editor. Acidic deposition and aquatic ecosystems: regional case studies. Springer-Verlag, New York, New York, USA.

Crouse, D. T., L. B. Crowder, and H. Caswell. 1987. A stagebased population model for loggerhead sea turtles and implications for conservation. Ecology 68:1412-1423.

Crowder, L. B., D. T. Crouse, S. S. Heppell, and T. H. Martin. 1994. Predicting the impact of turtle excluder devices on loggerhead sea turtle populations. Ecological Applications 4:437-445.

Cunjak, R. A., and J. M. Green. 1983. Habitat utilization by brook char (Salvelinus fontinalis) and rainbow trout (Salmo gairdneri) in Newfoundland streams. Canadian Journal of Zoology 61:1214-1219.

Cunjak, R. A., and J. M. Green. 1984. Species dominance by brook trout and rainbow trout in a simulated stream environment. Transactions of the American Fisheries Society 113:737-747.

DeAngelis, D. L., and L. J. Gross, editors. 1992. Individualbased models and approaches in ecology: populations, communities and ecosystems. Routledge, Chapman and Hall, New York, New York, USA.

Dill, L. M., R. C. Ydenberg, and A. H. G. Fraser. 1981. Food abundance and territory size in juvenile coho salmon (Oncorhynchus kisutch). Canadian Journal of Zoology 59: 1801-1809.

Dunham, A. E. 1993. Population responses to environmental change: operative environments, physiologically structured models, and population dynamics. Pages 95-119 in P. M. Kareiva, J. G. Kingsolver, and R. B. Huey, editors. Biotic interactions and global change. Sinauer Associates, Sunderland, Massachusetts, USA.

Ebenman, B., and L. Persson. 1988. Dynamics of size-structured populations, ecology and evolution. Springer-Verlag, New York, New York, USA.

Elliott, J. M. 1975. Number of meals in a day, maximum weight of food consumed in a day, and maximum rate of feeding for brown trout, Salmo trutta L. Freshwater Biology 5:287-303.

- 1984a. Growth, size, biomass and production of young migratory trout Salmo trutta in a Lake District stream, 1966-83. Journal of Animal Ecology 53:979-994. 1984b. Numerical changes and population regulation in young migratory trout Salmo trutta in a Lake District stream, 1966-83. Journal of Animal Ecology 53:327-350.

- 1985. Population regulation for different life-stages of migratory trout Salmo trutta in a Lake District stream, 1966-83. Journal of Animal Ecology 54:617-638.

. 1987. Population regulation in contrasting populations of trout Salmo trutta in two Lake District streams. Journal of Animal Ecology 56:83-98.

1989. Growth and size variation in contrasting pop- 
ulations of trout Salmo trutta: an experimental study on the role of natural selection. Journal of Animal Ecology 58: 45-58.

Evans, G. T., and J. B. Dempson. 1986. Calculating the sensitivity of a salmonid population model. Canadian Journal of Fisheries and Aquatic Sciences 43:863-868.

Fausch, K. D. 1989. Do gradient and temperature affect distributions of, and interactions between, brook charr ( $\mathrm{Sal}$ velinus fontinalis) and other resident salmonids in streams? Pages 303-322 in H. Kawanabe, F. Yamazaki, and D. L. G. Noakes, editors. Biology of Charrs and Masu Salmon. Physiology and Ecology Japan, Special Volume 1, Kyoto University, Kyoto, Japan.

Gibson, R. J., P. C. Kerkhoven, and R. L. Haedrich. 1976. The fecundity of unexploited brook trout populations in the Matamek River, Quebec. Naturaliste Canadien 103:417423.

Goodyear, C. P. 1980. Compensation in fish populations. Pages 253-280 in C. H. Hocutt and J. R. Stauffer, Jr., editors. Biological monitoring of fish. D. C. Heath, Lexington, Massachusetts, USA.

Hartshorn, G. S. 1975. A matrix model of tree population dynamics. Pages 41-51 in F. B. Golley and E. Medina, editors. Tropical ecological systems. Springer-Verlag, New York, New York, USA.

Helfrich, L. A., J. R. Wolfe, Jr., and P. T. Bromley. 1982. Agonistic behavior, social dominance, and food consumption of brook trout and rainbow trout in a laboratory stream. Proceedings of the Annual Conference of the Southeastern Association of Fish and Wildlife Agencies 36:340-352.

Horst, T. J. 1977. Use of the Leslie matrix for assessing environmental impact with an example for a fish population. Transactions of the American Fisheries Society 106 253-257.

Hunt, R. L. 1965. Dispersal of wild brook trout during their first summer of life. Transactions of the American Fisheries Society 94: 186-188.

. 1969. Overwinter survival of wild fingerling brook trout in Lawrence Creek, Wisconsin. Canadian Journal of Fisheries and Aquatic Sciences 26:1473-1483.

Ingersoll, C. G., D. R. Mount, D. D. Gulley, T. W. La Point, and H. L. Bergman. 1990. Effects of $\mathrm{pH}$, aluminum, and calcium on survival and growth of eggs and fry of brook trout (Salvelinus fontinalis). Canadian Journal of Fisheries and Aquatic Sciences 47:1580-1592.

Johnson, J. H. 1981. Food interrelationships of coexisting brook trout, brown trout, and yearling rainbow trout in tributaries of the Salmon River, New York. New York Fish and Game Journal 28:88-99.

Jordahl, D. M., and A. Benson. 1987. Effect of low pH on survival of brook trout embryos and yolk-sac larvae in West Virginia streams. Transactions of the American Fisheries Society 116:807-816.

Kalleberg, H. 1958. Observations in a stream tank of territoriality and competition in juvenile salmon and trout ( $\mathrm{Sal}$ mo salar and Salmo trutta). Institute of Freshwater Research, Drottningholm 39:55-98.

Kelly, G. A., J. S. Griffith, and R. D. Jones. 1980. Changes in distribution of trout in Great Smoky Mountains National Park, 1900-1977. U.S. Fish and Wildlife Service, Technical Paper Number 102, Washington, D.C., USA.

King, W. 1937. Notes on the distribution of native speckled and rainbow trout in the streams at Great Smoky Mountains National Park. Journal of the Tennessee Academy of Science 12:351-361.

Larson, G. L., and S. E. Moore. 1985. Encroachment of exotic rainbow trout into stream populations of native brook trout in the southern Appalachian mountains. Transactions of the American Fisheries Society 114:195-203.

Law, R., and D. R. Grey. 1988. Maximum sustainable yields and the self-renewal of exploited populations with agedependent vital rates. Pages 140-154 in B. Ebenman and L. Persson, editors. Size-structured populations: ecology and evolution. Springer-Verlag, New York, New York, USA.

LeCren, E. D. 1972. The population dynamics of young trout (Salmo trutta) in relation to density and territorial behaviour. Rapport et Procès-verbaux des Reunion Conseil Internationale pour l'Exploration de la Mer 164:241-246.

Leivestad, G. 1982. Physiological effects of acid stress in fish. Pages 157-164 in R. E. Johnson, editor. Acid rain/ fisheries. American Fisheries Society, Bethesda, Maryland, USA.

Lennon, R. E. 1967. Brook trout of Great Smoky Mountains National Park. U.S. Fish and Wildlife Service, Technica Paper Number 15, Washington, D.C., USA.

Lohr, S. C., and J. L. West. 1992. Microhabitat selection by brook and rainbow trout in a southern Appalachian stream. Transactions of the American Fisheries Society 121:729 736.

Marschall, E. A. 1991. Brook trout response to a changing environment: population consequences of growth and survival effects. Dissertation. North Carolina State University, Raleigh, North Carolina, USA.

Marschall, E. A., and L. B. Crowder. 1995. Density-dependent survival as a function of size in juvenile salmonids in streams. Canadian Journal of Fisheries and Aquatic Sciences 52:136-140.

Mason, J. C., and D. W. Chapman. 1965. Significance of early emergence, environmental rearing capacity, and behavioral ecology of juvenile coho salmon in stream channels. Canadian Journal of Fisheries and Aquatic Sciences 22:173-190.

McFadden, J. T. 1961. A population study of the brook trout, Salvelinus fontinalis. Wildlife Monographs 7.

McFadden, J. T., G. R. Alexander, and D. S. Shetter. 1967. Numerical changes and population regulation in brook trout Salvelinus fontinalis. Canadian Journal of Fisheries and Aquatic Sciences 24:1425-1459.

Metz, J. A. J., and O. Diekmann. 1986. The dynamics of physiologically structured populations. Springer-Verlag, Berlin, Germany.

Miller, J. M. 1970. An analysis of the distribution of youngof-the-year brook trout, Salvelinus fontinalis (Mitchill), in Lawrence Creek, Wisconsin. Dissertation. University of Wisconsin, Madison, Wisconsin, USA.

Mortensen, E. 1977. Density-dependent mortality of trout fry (Salmo trutta L.) and its relationship to the management of small streams. Journal of Fish Biology 11:613-617.

Mount, D. R., C. T. Ingersoll, D. D. Gulley, J. D. Fernandez, T. W. La Point, and H. L. Bergman. 1988. The effects of long-term exposure to acid, aluminum, and low calcium on adult brook trout (Salvelinus fontinalis): 1. Survival, growth, fecundity, and progeny survival. Canadian Journal of Fisheries and Aquatic Sciences 45:1623-1632.

Murdoch, W. W. 1993. Individual-based models for predicting effects of global climate change. Pages 147-166 in P. M. Kareiva, J. G. Kingsolver, and R. B. Huey, editors. Biotic interactions and global change. Sinauer Associates, Sunderland, Massachusetts, USA.

Needham, P. R. 1961. Observations on the natural spawning of eastern brook trout. California Fish and Game 47:2740 .

Newman, M. A. 1956. Social behavior and interspecific competition in two trout species. Physiological Zoology 29:6481.

Power, G. 1980. The brook charr, Salvelinus fontinalis. Pages 141-203 in E. Balon, editor. Charrs. Dr. Junk Publishers, The Hague, The Netherlands.

Powers, E. B. 1929. Fresh water studies. I. The relative tem- 
perature, oxygen concentration, alkali reserve, the carbon dioxide tension and $\mathrm{pH}$ of the waters of certain mountain streams at different altitudes in the Smoky Mountain National Park. Ecology 10:97-111.

Ricker, W. E. 1954. Stock and recruitment. Journal of the Fisheries Research Board of Canada 11:559-623.

Rose, G. A. 1986. Growth decline in subyearling brook trout (Salvelinus fontinalis) after emergence of rainbow trout (Salmo gairdneri). Canadian Journal of Fisheries and Aquatic Sciences 43:187-193.

Slaney, P. A., and T. G. Northcote. 1974. Effects of prey abundance on density and territorial behaviour of young rainbow trout (Salmo gairdneri) in laboratory stream channels. Canadian Journal of Fisheries and Aquatic Sciences 31: 1201-1209.

Slobodkin, L. B. 1968. How to be a predator. American Zoologist 8:43-51.

Titus, R. G., and H. Mosegaard. 1991. Selection from growth potential among migratory brown trout (Salmo trutta) fry competing for territories: evidence from otoliths. Canadian Journal of Fisheries and Aquatic Sciences 48:19-27.

Urwick, R. S. 1986. A comparison of life histories of brook trout in allopatric and sympatric populations in a western
North Carolina stream. Thesis. Western Carolina University, Cullowee, North Carolina, USA

Van Winkle, W., S. W. Christensen, and J. E. Breck. 1986. Linking laboratory and field responses of fish populations to acidification. Water, Air, and Soil Pollution 30:639-648.

Whitworth, W. E., and R. J. Strange. 1983. Growth and production of sympatric brook and rainbow trout in an Appalachian stream. Transactions of the American Fisheries Society 112:469-475.

Witzel, L. D., and H. R. MacCrimmon. 1983a. Embryo survival and alevin emergence of brook charr, Salvelinus fontinalis, and brown trout, Salmo trutta, relative to redd gravel composition. Canadian Journal of Zoology 61:1783-1792.

Witzel, L. D., and H. R. MacCrimmon. 1983b. Redd-site selection by brook trout and brown trout in southwestern Ontario streams. Transactions of the American Fisheries Society 112:760-771.

Wood, C. M., and D. G. McDonald. 1982. Physiological mechanisms of acid toxicity to fish. Pages 197-226 in R. E. Johnson, editor. Acid rain/fisheries. American Fisheries Society, Bethesda, Maryland, USA.

Wydoski, R. S., and E. L. Cooper. 1966. Maturation of brook trout from infertile streams. Canadian Journal of Fisheries and Aquatic Sciences 23:623-649. 